\title{
CHARACTERS, DETERMINANTS, AND ASSOCIATION BETWEEN CHRONIC ANEMIA AND ATRIAL FIBRILLATION: CASE-CONTROL STUDY
}

\author{
HAIDER SHAHEED MOHAMMED* \\ Department of Internal Medicine, College of Medicine, University of Thi-Qar, Iraq. Email: layla.alhassan14@gmail.com
}

Received: 10 October 2019, Revised and Accepted: 11 December 2019

\begin{abstract}
Objective: The objective of this study was carried out to study the characters, determinants of anemia among atrial fibrillation (AF) patients and to estimate the link between chronic anemia and AF.

Methods: This is a case-control study, administrated in Al-Hussein Teaching Hospital among admitted patients in the cardiac care unit from $1^{\text {st }}$ week of January 2018 to the last week of April 2019. A random sample of 100 patients was included in the study based cut of time, where a special form of inquiry sheet was constructed to gather data and it was reviewed and revised by matter experts for testing the validity and enrichment of it. Both cases of AF and control with sinus rhythm were divided into anemic and non-anemic, anemia is defined as hemoglobin $<13$ and $<12$ in male and female, respectively. A Statistical Package for the Social Sciences (SPSS) version (25) was used for data analysis. Descriptive statistics Chisquare Fischer exact test, and ANOVA tests of significance, correlation and logistic regression analysis had been estimated where $\mathrm{p}<0.05$ was set as statistically significant.
\end{abstract}

Results: A total of 100 individuals had been included in the study, 50 cases with AF and 50 control with mean of age was $62.74003 \pm 13.424$ years 58 females with 42 males, total non-anemic was 57 while total anemic was $43,74.4 \%$ of AF cases was anemic while $25.6 \%$ of control group was anemic, there was statistically significant difference between cases and control according to the presence and absence of anemia where $\mathrm{p}<0.05$.

Conclusion: The first study done in the region to prove the direct relation of anemia on incident AF, thus in conclusion, chronic anemia had a relation with AF.

Keywords: Anemia, Atrial fibrillation.

(C) 2020 The Authors. Published by Innovare Academic Sciences Pvt Ltd. This is an open access article under the CC BY license (http://creativecommons. org/licenses/by/4. 0/) DOI: http://dx.doi.org/10.22159/ajpcr.2020.v13i2.36024

\section{INTRODUCTION}

Atrial fibrillation (AF) "is a supraventricular tachyarrhythmia characterized by uncoordinated atrial activation with consequent deterioration of atrial mechanical function" [1]. AF is the most frequent heart rhythm disturbance [2] distressing $10 \%$ of individuals older than 80 years of age [3]. Nearly one in four persons will experience AF throughout life [4]. The incidence of $\mathrm{AF}$ is like prevalence rises with age [5] and is more in males than females across all age categories [6]. One of the preventive measures of AF is decreasing weight and practicing regular exercise $[7,8]$ with rigorous controlling of predisposing conditions leading to decrement in its morbidity impact and its rigorousness [9]. AF seems to attack chiefly the elderly individuals and nearly $80 \%$ of all individuals suffering AF are older than 65 years of age and during the year 2050 , this rise into about $88 \%$ [10]. Individuals with AF have 2 times the risk of death to those without such condition probably because of related chronic disorders, involving anemia, in AF patients [10]. AF is linked to an excess hazard of initiation of cardiac failure [9]. The occurrence of AF and chronic disorders concurrently not just incorporates to morbidity load but seems to be an unfavorable agent in deterioration of events [10]. In $10 \%$ of persons with $\mathrm{AF}$, it is occurred without an identifiable concurrent predisposing disorder; nevertheless, AF is generally linked with other heart disorders encompassing hypertension, cardiac failure, diabetes mellitus (DM), and coronary artery disease, among others $[9,11]$. "Anemia is defined as reduced hemoglobin concentration or hematocrit" [10]. The prevalence of anemia is nearly $10 \%$ in individuals older than 65 years old, and nearly $20 \%$ in those more than 85 years old [12]. Anemia is frequently occurred concurrently with chronic disorders such as cardiac insufficiency and DM and emerged as an unbiased prognosticator for unfavorable consequences linked alongside those disorders [13]. The prevalence of anemia is more in elderly persons and appeared to rise with old age and with rising in comorbidity loading [10]. The concurrent $\mathrm{AF}$ and anemia largely raising the morbidity load [10]. Anemia emerged as an unbiased prognosticator of fatality along with hospital admission in senile individuals with AF regardless of associated chronic disorders and the use of cardiac drugs $[10,14]$. In individuals with AF, anemia obviously anticipates worse consequences [15]. The anemia seems to be an adjusted predisposing condition for AF, which proposes that addressing and management of anemia probably ameliorate the prospects of individuals with this disorder [10]. The prevalence of AF is increasing morbidity, and constitutes a public and worldwide health-care issue leading to the death and economic burden [16]. Hence, management and addressing risk factors of $\mathrm{AF}$ is major aim to decrease the health impact of AF [15]. Anemia is frequently encountered in patient with $\mathrm{AF}$ and might add to health-care exhaustion and burden with more adverse consequences [15]. Hemoglobin is a valuable prognosticator for anticipating cardiac catastrophes in AF [14]. Anemia raising death and adverse consequences in heart disorders [13], so anemia could be a crucial modifiable predisposing factor for AF that is screening and adequate management of anemia in those population could decrease the clinical and morbidity impact. The aim of the current study was to estimate the link between chronic anemia and $\mathrm{AF}$, which might affect decreasing the morbidity burden of $\mathrm{AF}$ by adequate screening and treatment of anemia in those populations.

\section{METHODS}

This study had been extended from $1^{\text {st }}$ week of January 2018 to the last week of April 2019 and included the admitted patients in the cardiac care unit of Al-Hussein Teaching Hospital in Al-Nasiriya city. The cases were diagnosed depending on any available reports, investigations or diagnosed on arrival to the cardiac care unit. 


\section{Exclusion criteria}

1. Acute anemia is due to either acute blood loss or acute hemolysis

2. The defaulters in the study reported as refusal, even though the refusal rate was zero, especially when the researcher explained the purpose of the study.

\section{Sampling size}

The sampling size was a convenient sample, limited by the availability of the patients, but the sampling process for control, a systematic random sampling procedures were used to collect controls.

\section{Study appliances}

The inquiry: Distinct design of inquiry had been constructed to gather data, and it was reviewed and revised by three subject matter experts (of community medicine and physician) for testing the validity and enrichment of the questionnaire. The inquiry consisted of three partitions:

- Partition (1): Involves questions related to identity information (name, age, gender, address, marital status, education level, and occupation).

- Partition (2): Involves questions related to medical history to explore any underlying predisposing condition for $\mathrm{AF}$ and chronic disease association.

- Partition (3): Involves questions related to drug history including number, type, and the patient had used dosage of medications.

\section{Diagnostic procedures}

All admitted participants with AF are subjected to thorough evaluation consisting of history, clinical examination, and body mass index (BMI). Electrocardiogram, and echocardiography, baseline laboratory studies involving complete blood count, renal indices, thyroid-stimulating hormone (TSH), and blood glucose.

$\mathrm{AF}$ is diagnosed by electrocardiogram, "AF is characterized by the replacement of consistent $p$ waves by rapid oscillation or fibrillatory waves that vary in amplitude, shape timing associated with an irregular, frequently rapid ventricular response when (atrioventricular) conduction is intact" [1]. Anemia is diagnosed according to the World Health Organization (WHO) standards, WHO determination for anemia in men and women is hemoglobin $<13$ and $<12 \mathrm{~g} / \mathrm{dl}$, respectively $\mathrm{p}<0.05$. All control subjects with sinus rhythm are sex- and agedmatched and subjected to evaluation by pre-constructed inquiry sheet consisting of identity information (name, age, sex, marital state, job, residency, and education state). A complete blood count was done for all control subjects.

Normal values of predefined investigations had been already defined for the team of workers. The data immediately recorded in the inquiry sheet at the research place then reviewed every day and week. A questionnaire strategy was used for recording and the questionnaire information were pre-coded by employing of Statistical Package for the Social Science (SPSS) version (25).

\section{Statistical analysis}

SPSS version (25) had been employed for data evaluation, descriptive statistics, frequencies, percentages, associations, and test of significance (Chi-square test or Fisher exact test, t-test, and ANOVA test) had been used for analysis of categorical variables, means and standard deviations were used to present data of continuous variables. $p<0.05$ was fixed as a statistically significant.

\section{RESULTS}

Case-control study has been implemented to study the characters, determinants of chronic anemia and its relation to AF patients were 50 cases (mean age: $62.740031 \pm 13.424$ ), and 50 sex- and age-matched controls were selected and were described as the following:

Even though most of our presented samples were with a mean age of $62.740031 \pm 13.424$, female gender, married, and primary and literal educational status but there was no statistically significant association between demographic character and anemia, as shown in Table 1a and $b$. Even though there was no statistically significant association between occupation and anemia $(\mathrm{p}=0.887)$, most of our sample were housewife females, as shown in Fig. 1.

Even though there was no statistical association between address and anemia $(\mathrm{p}=0.785)$, most of our sample inhabiting Al-Nasiriyah (59\%), other districts were presented in nearly comparable percent, as shown in Fig. 2.

Table 1a: Anemia distribution according to age

\begin{tabular}{lllll}
\hline Anemia & $\mathbf{n}$ & Mean of age & Standard deviation & t, P value \\
\hline Absent & 57 & 62.4211 & 13.43895 & -0.273 \\
Present & 43 & 63.1628 & 13.41096 & 0.785 \\
\hline
\end{tabular}

Table 1b: Distribution of anemia according to the demography of studied population

\begin{tabular}{|c|c|c|c|c|}
\hline \multirow[t]{2}{*}{ Parameter } & \multicolumn{2}{|l|}{ Anemia } & \multirow[t]{2}{*}{ Total, n (\%) } & \multirow{2}{*}{$\begin{array}{l}\chi^{2} \\
\text { p value }\end{array}$} \\
\hline & $\begin{array}{l}\text { Absent, } \\
\text { n (\%) }\end{array}$ & $\begin{array}{l}\text { Present, } \\
\text { n (\%) }\end{array}$ & & \\
\hline \multicolumn{5}{|l|}{ Sex } \\
\hline Male & $24(57.1)$ & $18(42.9)$ & $42(100.0)$ & $0.001^{\mathrm{a}}$ \\
\hline Female & 33 (56.9) & 25 (43.1) & $58(100.0)$ & 0.162 \\
\hline \multicolumn{5}{|l|}{ Marital status } \\
\hline Single & $4(57.1)$ & $3(42.9)$ & $7(100.0)$ & $0.000^{\mathrm{a}}$ \\
\hline Married & $53(57.0)$ & $40(43.0)$ & $93(100.0)$ & 0.305 \\
\hline \multicolumn{5}{|l|}{ Education } \\
\hline $\begin{array}{l}\text { Primary and } \\
\text { illiterate }\end{array}$ & 33 (57.9) & $24(42.1)$ & $57(100.0)$ & $0.138^{\mathrm{a}}$ \\
\hline Secondary & $9(52.9)$ & $8(47.1)$ & $17(100.0)$ & 0.986 \\
\hline $\begin{array}{l}\text { Basic college } \\
\text { and above }\end{array}$ & $15(57.7)$ & $11(42.3)$ & $26(100.0)$ & \\
\hline Total & $57(57.0)$ & $43(43.0)$ & $100(100.0)$ & \\
\hline
\end{tabular}

"a" refer to highly significant than other values such as "b" or "c"

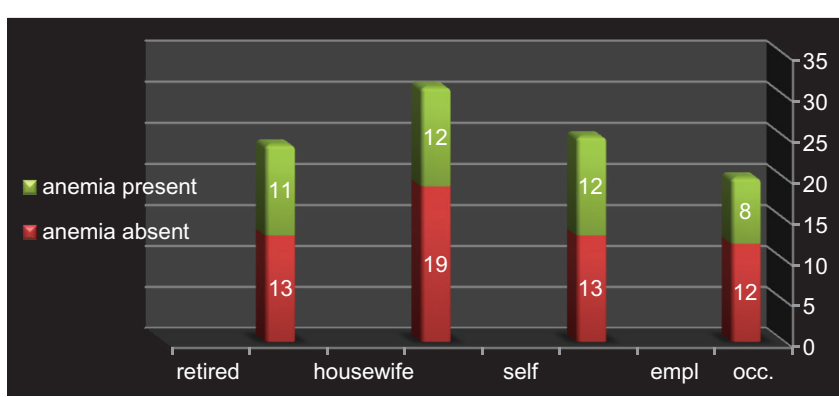

Fig. 1: District of anemia according to the occupation $(p=0.887)$

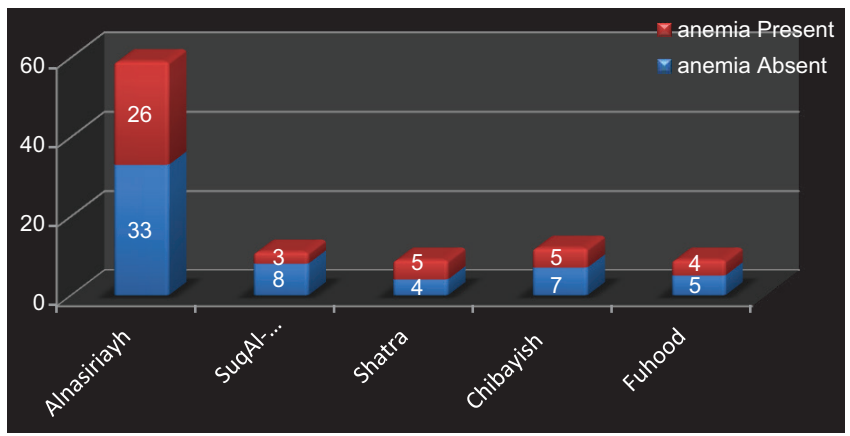

Fig. 2: Distribution of anemia in accordance with residence (Chisquare $=1.733^{\mathrm{a}} \mathrm{p}=\mathbf{0 . 7 8 5}$ 
There was very high statistically significant difference between cases and control according to the presence and absence of anemia where $(\mathrm{p}<0.0001)$, as shown in Table 2 . There was a statistically significant association between the number of drugs that had been used among $\mathrm{AF}$ cases with a status of anemia $(\mathrm{p}=0.029)$, as shown in Fig. 3, Chi-square $=18.864 \mathrm{p}=0.029$.

According to the echocardiographic findings, there was a statistically significant association between the number of echocardiographic abnormalities and anemia $(\mathrm{p}=0.0321)$

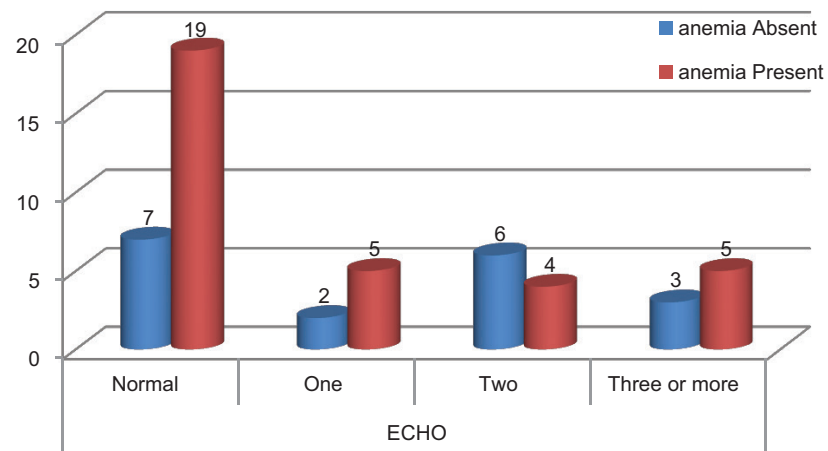

According to the cardiovascular diseases had been assessed in research, there was statistically significant association between valvular heart disease (VHD) and status of anemia $(p=0.003)$ while hypertension, heart failure, ischemic heart disease, and cardiomyopathy do not show such an association $\mathrm{p}=0.832,0.375,0.294$, and 0.640 , respectively, as shown in Table 3.

According to the metabolic diseases had been assessed in research, there was a statistically significant association between DM and anemia $(\mathrm{p}=0.026)$ while other metabolic diseases such as hypothyroidism, hyperthyroidism, metabolic syndrome, and obesity do not show such association.

According to the miscellaneous diseases assessed in research, there was a statistically significant association between chronic kidney disease (CKD) and anemia ( $p=0.039)$, while there was no significant association between chronic obstructive pulmonary disease (COPD) and anemia $(\mathrm{p}=0.255)$, as shown in Table 5

There was a very high statistically significant association between serum creatinine, TSH and anemia ( $\mathrm{p}=0.0001$ for both), while there was a highly statistically significant association between blood urea and anemia $(\mathrm{p}=0.001)$, as shown in Table 6.

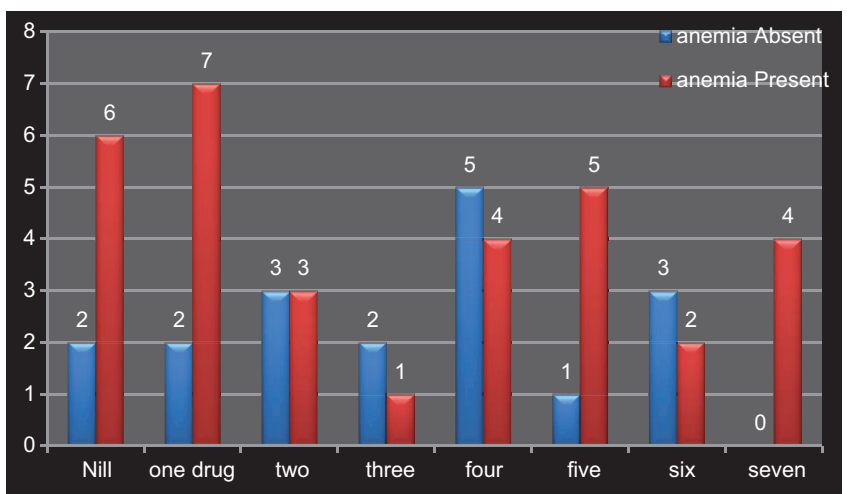

Fig. 3: Relationship between number of drugs and status of anemia (Chi-square $\left.=15.862^{\mathrm{a}} \mathrm{p}=0.0321\right) \mathrm{ECHO} *$ anemia
Table 2: Distribution of anemia among AF cases and control

\begin{tabular}{lllll}
\hline Parameter & \multicolumn{2}{l}{ Cases and control } & \multirow{2}{*}{ Total, n (\%) } & $\chi^{2}$ \\
\cline { 2 - 3 } \cline { 5 - 5 } & $\mathbf{A F}, \mathbf{n}(\%)$ & Control, n (\%) & & p value \\
\hline Anemia & & & & \\
Absent & $18(31.6)$ & $39(68.4)$ & $57(100.0)$ & $<0.05^{\mathrm{a}}$ \\
Present & $32(74.4)$ & $11(25.6)$ & $43(100.0)$ & 0.0001 \\
Total & $50(50.0)$ & $50(50.0)$ & $100(100.0)$ & \\
\hline
\end{tabular}

AF: Atrial fibrillation

Table 3: Distribution of anemia according to the cardiovascular disease among atrial fibrillation

\begin{tabular}{|c|c|c|c|c|}
\hline \multirow[t]{2}{*}{ Parameter } & \multicolumn{2}{|l|}{ Anemia } & \multirow[t]{2}{*}{ Total, n (\%) } & \multirow{2}{*}{$\frac{\chi^{2}}{\text { p value }}$} \\
\hline & $\begin{array}{l}0.00 \\
\text { n (\%) }\end{array}$ & $\begin{array}{l}1.00 \\
\text { n (\%) }\end{array}$ & & \\
\hline \multicolumn{5}{|l|}{ Hypertension } \\
\hline No & $9(37.5)$ & $15(62.5)$ & $24(100.0)$ & $0.045^{\mathrm{a}}$ \\
\hline Yes & $9(34.6)$ & $17(65.4)$ & $26(100.0)$ & 0.832 \\
\hline \multirow{2}{*}{$\begin{array}{l}\text { Congestive heart } \\
\text { failure }\end{array}$} & $12(32.4)$ & $25(67.6)$ & $37(100.0)$ & $0.786^{\mathrm{a}}$ \\
\hline & $6(46.2)$ & 7 (53.8) & $13(100.0)$ & 0.375 \\
\hline \multirow{2}{*}{$\begin{array}{l}\text { Valvular heart } \\
\text { disease }\end{array}$} & 8 (22.9) & $27(77.1)$ & $35(100.0)$ & $8.747^{a}$ \\
\hline & $10(66.7)$ & $5(33.3)$ & $15(100.0)$ & 0.003 \\
\hline \multirow{2}{*}{$\begin{array}{l}\text { Ischemic heart } \\
\text { disease }\end{array}$} & 15 (34.9) & $28(65.1)$ & $43(100.0)$ & $0.166^{\mathrm{a}}$ \\
\hline & 3 (42.9) & $4(57.1)$ & $7(100.0)$ & 0.294 \\
\hline \multirow[t]{2}{*}{ Cardiomyopathy } & $18(36.7)$ & $31(63.3)$ & $49(100.0)$ & $0.574^{\mathrm{a}}$ \\
\hline & $0(0.0)$ & $1(100.0)$ & $1(100.0)$ & 0.640 \\
\hline Total & $18(36.0)$ & $32(64.0)$ & $50(100.0)$ & \\
\hline
\end{tabular}

"a" refer to highly significant than other values such as "b" or "c"

Table 4: Distribution of anemia according to the metabolic diseases among atrial fibrillation patients

\begin{tabular}{lllll}
\hline Parameter & \multicolumn{2}{l}{ Anemia, n (\%) } & Total, n (\%) & $\boldsymbol{\chi}^{\mathbf{2}}$ \\
\cline { 2 - 3 } \cline { 5 - 5 } & $\mathbf{0 . 0 0}$ & $\mathbf{1 . 0 0}$ & & $\mathbf{p}$ value \\
\hline Hyperthyroidism & & & & \\
$\quad$ No & $17(36.2)$ & $30(63.8)$ & $47(100.0)$ & 0.010 \\
$\quad$ Yes & $1(33.3)$ & $2(66.7)$ & $3(100.0)$ & 0.465 \\
Hypothyroidism & $17(40.5)$ & $25(59.5)$ & $42(100.0)$ & $2.283^{\text {a }}$ \\
& $1(12.5)$ & $7(87.5)$ & $8(100.0)$ & 0.113 \\
Diabetes mellitus & $15(46.9)$ & $17(53.1)$ & $32(100.0)$ & $4.563^{\mathrm{a}}$ \\
Metabolic & $3(16.7)$ & $15(83.3)$ & $18(100.0)$ & 0.026 \\
syndrome & $17(36.2)$ & $30(63.8)$ & $47(100.0)$ & $0.010^{\mathrm{a}}$ \\
Obesity & $1(33.3)$ & $2(66.7)$ & $3(100.0)$ & 0.856 \\
Total & $17(37.0)$ & $29(63.0)$ & $46(100.0)$ & 0.228 \\
\hline
\end{tabular}

"a" refer to highly significant than other values such as "b" or " $c$ "

Table 5: Miscellaneous diseases (COPD and CKD) with anemia

\begin{tabular}{|c|c|c|c|c|}
\hline \multicolumn{4}{|c|}{ Crosstab } & \multirow{3}{*}{$\frac{\chi^{2}}{\text { p value }}$} \\
\hline \multirow[t]{2}{*}{ COPD } & \multicolumn{2}{|c|}{ Anemia, n (\%) } & \multirow[t]{2}{*}{ Total, n (\%) } & \\
\hline & 0.00 & 1.00 & & \\
\hline No & $16(34.0)$ & $31(66.0)$ & $47(100.0)$ & $1.303^{\mathrm{a}}$ \\
\hline Yes & $2(66.7)$ & $1(33.3)$ & $3(100.0)$ & 0.255 \\
\hline \multicolumn{5}{|l|}{ CKD } \\
\hline No & $15(45.5)$ & $18(54.5)$ & $33(100.0)$ & 3.766 \\
\hline Yes & $3(17.6)$ & $14(82.4)$ & $17(100.0)$ & 0.039 \\
\hline Total & $18(36.0)$ & $32(64.0)$ & $50(100.0)$ & \\
\hline
\end{tabular}

CKD: Chronic kidney disease, COPD: Chronic obstructive pulmonary disease 
Table 6: Group statistics

\begin{tabular}{llllll}
\hline Anemia & n & Mean & $\begin{array}{l}\text { Standard } \\
\text { deviation }\end{array}$ & ANOVA & p value \\
\hline $\begin{array}{l}\text { Age } \\
\quad \text { Normal }\end{array}$ & 18 & 66.2222 & 12.13917 & 2.526 & 0.119 \\
$\quad$ Anemia & 32 & 60.7188 & 14.47854 & & \\
$\begin{array}{l}\text { Blood urea } \\
\quad \text { Normal }\end{array}$ & 18 & 38.7222 & 24.30155 & 13.375 & 0.001 \\
$\quad$ Anemia & 32 & 55.7813 & 36.72718 & & \\
$\quad \begin{array}{l}\text { Serum creatinine } \\
\quad \text { Normal }\end{array}$ & 18 & 1.1483 & 0.53023 & 25.749 & 0.0001 \\
$\quad$ Anemia & 32 & 1.8622 & 1.22222 & & \\
$\begin{array}{l}\text { Random blood sugar } \\
\quad \text { Normal }\end{array}$ & 18 & 165.2778 & 56.05964 & 7.910 & 0.007 \\
$\quad \begin{array}{l}\text { Anemia } \\
\text { Anemia }\end{array}$ & 32 & 195.5938 & 84.00993 & & \\
$\begin{array}{l}\text { Thyroid-stimulating } \\
\text { hormone }\end{array}$ & 32 & 4.0813 & 1.60793 & & \\
$\quad \begin{array}{l}\text { Normal } \\
\text { Anemia }\end{array}$ & 18 & 3.43556 & 1.640065 & 14.655 & 0.000 \\
\hline
\end{tabular}

\section{DISCUSSION}

A hospital-based case-control study extended over 1 year and 4 months to include 50 patients admitted to the cardiac care unit in Al-Hussein Teaching Hospital in Al-Nasiriya city with 50 controls to study the character, determinants, and association between chronic anemia and $\mathrm{AF}$.

In the current study, we found an association between $\mathrm{AF}$ and chronic anemia; there is very high statistically significant difference between cases and controls according to the presence and absence of anemia where $\mathrm{p}<0.00001$. Xu et al. [17] establish that anemia and chronic renal failure, lonely and in mix had been intimated with a heightened anger of recent commencement of $\mathrm{AF}(\mathrm{p}<0.0001)$. On the other side retrospective cohort study of Medicare patients lacking the previous AF or advanced kidney disease who were followed up for 2 years, end-stage chronic renal failure alongside anemia had been exclusively compounded with episode of AF (hazard ratio 1.13, 95\% confidence interval 1.091.18, $\mathrm{p}<00001$ and 1.05, 1.03-1.07, $\mathrm{p}<0.0001$ ) [18]. Our findings are inconsistent with study cohort of senile population who conclude that long-standing anemia is not correlated with recent AF; this might be due to different types and designs of study or size of the sample [19]. Regarding socio-demographic character in our study, cases and controls were well crossly matched to avoid selection bias so there was no statistically significant association between sociodemography of cases and controls with the anemia. Regarding association of anemia with the number of drugs that had been used, there is statistically significant association between number of drugs had been used by the patients and status of anemia $(p=0.029)$ this reflecting those who have had more cardio tropic drugs used likely had more comorbid clinical conditions and anemia is more prevalent among patients with large morbidity burden $[20,21]$. Most of our patients participating in the study were utilized angiotensin-converting enzyme inhibitor (ACEI), angiotensin receptor blockers (ARBs), metformin, thiazolidinedione and sulfonylureas. Prolonged use of metformin might cause megaloblastic anemia, in few case studies, consumption of sulfonylureas have been associated with hemolytic anemia, while the use of ACEI and ARBs may precipitate anemia by direct blockade of degradation of physiological inhibitors of hematopoiesis [22]. In addition, using thiazolidinedione may be caused anemia due to fat accumulation in bone marrow [22]. Regarding cardiovascular diseases in our study, we did not found an association between hypertension with anemia $(\mathrm{p}=0.832)$. Our findings are similar to Lee et al., [14] who demonstrate that hypertension is not associated with anemia among AF patients $(\mathrm{p}=0.694)$. In our study, chronic heart failure and coronary artery diseases were not found to be associated with anemia ( $p=0.375$ and 0.294 , respectively), and this is inconsistent with Lee et al. [14], this can be explained by nonsplitting of the patients or classifying them according to the duration of the disease development which was not our interest in the study where newly developed cases mixed with established cases which might have years of duration. Our study demonstrates an association between anemia and VHD ( $\mathrm{p}=0.003)$ and this is consistent with Harsha et al. [19] In our study, among metabolic diseases that predispose to AF DM is significantly associated with anemia $(\mathrm{p}=0.026)$, this is consistent with Westenbrink et al. [15] who demonstrate DM is associated with anemia $(\mathrm{p} \leq 0.0001)$. While hypothyroidism and hyperthyroidism both are not associated with anemia ( $\mathrm{p}$ values for hypothyroidism and hyperthyroidism are 0.113 and 0.465 , respectively) and this is consistent with Floriani et al. [23], a population based a cohort study which found that subclinical thyroid dysfunction and overt thyroid dysfunction were not associated with change in hemoglobin concentration but TSH is significantly associated with anemia in our study ( $p=0.0001)$ this can be explained as follows: Although large proportion of thyroid dysfunction are unrecognized [24], so by application of TSH which is the screening test of choice for the detection of unrecognized cases [24], there is statistically significant association and when we depend on only known cases of thyroid dysfunction by history we found no statistically significant association because these disorders might undergo treatment for various complications of thyroid dysfunction the most important of which is anemia [25]. In our study, AF is not associated with BMI ( $p=0.388)$ and this is consistent with Lee et al., [14] ( $\mathrm{p}=0.171$ ). Our study demonstrate non-significant association between COPD and anemia and this is not consistent with Harsha et al. [19] which found significant association between anemia and COPD ( $\mathrm{p}=0.0001)$, this might be due to different type or design of the study, or different population. CKD is found to be associated with anemia $(\mathrm{p}=0.039)$, this is consistent with Takabayashi et al. [26] ( $\mathrm{p}=0.001)$. Among biochemical tests used in our study random blood sugar were found to have a significant association with anemia ( $p=0.007$ ) this is consistent with Jessica et al. [27]. Renal function tests were found to have statistically significant association with anemia, Abudulmajeed et al. [28] demonstrate similar findings. Finally, our study demonstrate statistically significant association between anemia and increasing number of echocardiographic findings $(\mathrm{p}=0.0321)$ and this reflect anemia is associated with comorbidities including increased cardiovascular comorbidities such as left ventricular dysfunction and left ventricular hypertrophy, this finding was similar to what was found by study done by Sarin et al. [29]. The discrepancy between demonstrating statistically significant association between echocardiographic findings with anemia and demonstrating statistically non-significant statistical association between history of cardiac diseases such as hypertension, coronary artery diseases, and chronic heart failure with anemia might be explained as: The number of echocardiographic findings is caused by more than one disease. Lack of follow-up because of the study design and this can be the limitation of our study.

\section{CONCLUSION}

Chronic anemia had a relation with the occurrence of new-onset AF.

\section{ACKNOWLEDGMENTS}

The author is gratitude to the people who contributed in different ways to the research. Foremost I thank all the patients who participated in this research.

\section{AUTHORS' CONTRIBUTIONS}

The author has contributed to the design and implementation of the research, to the analysis of the results and to the writing of the manuscript.

\section{CONFLICTS OF INTERSET}

I declare that there are no conflicts of interest.

\section{ETHICAL CONSIDERATION}

An ethical license was acquired from Al-Hussein hospital administration. An informed consent also was taken from all participants. 


\section{REFERENCES}

1. Oreoluwa O, Ifeanyi N. Stroke risk stratification in atrial fibrillation: A review of common risk factors. J Community Hosp Intern Med Perspect 2019;9:113-20.

2. Ferrari R, Bertini M, Blomstrom-Lundqvist C, Dobrev D, Kirchhof P, Pappone C, et al. An update on atrial fibrillation in 2014: From pathophysiology to treatment. Int J Cardiol 2016;203:22-9.

3. Nikolaos K, Konstantinos PL, Konstantinos V, Georgopoulos S, Bakalakos A, Efremidis M, et al. Managing atrial fibrillation in the very elderly patient: Challenges and solutions. Vasc Health Risk Manag 2015;11:555-62.

4. Mou L, Norby FL, Chen LY, O'Neal WT, Lewis TT, Loehr LR, et al. Lifetime risk of atrial fibrillation by race and socioeconomic status: ARIC (atherosclerosis risk in communities). Circ Arrhythm Electrophysiol 2018;11:e006350.

5. Boriani G. Atrial fibrillation and aging: Risky mutual relationships. Chest 2016;149:301-2.

6. Ko D, Rahman F, Schnabel RB, Yin X, Benjamin EJ, Christophersen IE, et al. Atrial fibrillation in women: Epidemiology, pathophysiology, presentation, and prognosis. Nat Rev Cardiol 2016;13:321-32.

7. Van Gelder IC, Hobbelt AH, Brügemann J, Rienstra M. Time to implement fitness and reduction of fatness in atrial fibrillation therapy. Europace 2017;19:513-4.

8. Camille L, Ioanna T, Karel GM, Sweeting M, Boer J, Johnson L, et al. Separate and combined associations of obesity and metabolic health with coronary heart disease: A pan-European case-cohort analysis. Eur Heart J 2018;39:397-406.

9. Axel B, Marcelle DS, Bao ON, Rienstra M, Van Gelder IC. Risk factor management in atrial fibrillation. Arrhythm Electrophysiol Rev 2018;7:118-27.

10. Ali AN, Athavale NV, Abdelhafiz AH. Anemia: An independent predictor of adverse outcomes in older patients with atrial fibrillation. J Atr Fibrillation 2016;8:1366.

11. Wijesurendra RS, Liu A, Eichhorn C, Ariga R, Levelt E, Clarke WT, et al. Lone atrial fibrillation is associated with impaired left ventricular energetics that persists despite successful catheter ablation. Circulation 2016;134:1068-81

12. Lawrence TG, Stanley LS. Evaluation and management of anemia in the elderly. Am J Hematol 2014;89:88-96.

13. Mozos I. Mechanisms linking red blood cell disorders and cardiovascular diseases. Biomed Res Int 2015;2015:682054.

14. Lee WH, Hsu PC, Chu CY, Lee HH, Lee MK, Lee CS, et al. Anemia as an independent predictor of adverse cardiac outcomes in patients with atrial fibrillation. Int J Med Sci 2015;12:618-24.

15. Westenbrink BD, Alings M, Granger CB, Alexander JH, Lopes RD,
Hylek EM, et al. Anemia is associated with bleeding and mortality, but not stroke, in patients with atrial fibrillation: Insights from the apixaban for reduction in stroke and other thromboembolic events in atrial fibrillation (Aristotle) trial. Am Heart J 2017;185:140-9.

16. Carlos AM, Amitava B, Pablo P, Wood D, Jouven X. Atrial fibrillation: The current epidemic. J Geriatr Cardiol 2017;14:195-203.

17. Xu D, Murakoshi N, Sairenchi T, Irie F, Igarashi M, Nogami A, et al. Anemia and reduced kidney function as risk factors for new onset of atrial fibrillation(from the Ibaraki prefectural health study). Am J Cardiol 2015;115:328-33.

18. Sarah EN, Gautam RS, Shuling L, Herzog CA. Impact of chronic kidney disease on risk of incident atrial fibrillation and subsequent survival in medicare patients. J Am Heart Assoc 2012;1:e002097.

19. Harsha VG, Nandini K, Bridget ZM, Miller WL. Impact of chronic anemia on the new-onset atrial fibrillation in the elderly: It may not be what we have thought. J Atr Fibrillation 2012;4:515.

20. Migone DA, Poggiali E, Motta I, Minonzio F, Fabio G, Hu C, et al. Anemia in elderly hospitalized patients: Prevalence and clinical impact. Intern Emerg Med 2015;10:581-6.

21. Shamaila B, Muhammad F, Ahsan AA. Anemia in elderly hospitalized patients: Frequency and association with comorbidities. JIIMC 2018;13:194-9.

22. Sahay M, Kalra S, Tiwaskar M, Ghosh S, Badani R, Bantwal G, et al. Indian college of physicians position statement on anemia in metabolic syndrome. J Assoc Physicians India 2017;65:60-73.

23. Floriani C, Feller M, Aubert CE, M'Rabet-Bensalah K, Collet TH, den Elzen WP, et al. Thyroid dysfunction and anemia: A prospective cohort study and a systemic review. Thyroid 2018;28:575-82.

24. LeFevre ML, U.S. Preventive Services Task Force. Screening for thyroid dysfunction: U.S. Preventive service task force recommendation statement. Ann Intern Med 2015;162:641-50.

25. Szczepanek-Parulska E, Hernik A, Ruchala M. Anemia in thyroid disease. Pol Arch Intern Med 2017;127:352-60.

26. Takabayashi K, Unoki T, Ogawa H, Esato M, Chun YH, Tsuji H, et al. Clinical characteristics of atrial fibrillation patients with anemia: From the Fushimi AF registry. Eur Heart J 2013;34:389.

27. Jessica B, Paula CF, Eliane RW, Zimmermann CE, Sandri YP, Mallet EK, et al. Anemia in patients with Type 2 diabetes mellitus. Anemia 2015;2015:354737.

28. Abudulmajeed HA, Methaq AA, Abdulrahman BA, Alomair AM, Alomair AA, Aldossari NA, et al. The relation between diabetes Type II and anemia. Egypt J Hosp Med 2018;70:526-31.

29. Sarin S, Tejinder T, Agrawal BK, Sharma T. An echocardiographic study of cardiac functions in patients with severe anemia. Int J Appl Res 2016;2:233-5. 